March - 2010

\title{
“Can you hear me, Hanoi?" Compensatory Mechanisms Employed in Synchronous Net-Based English Language Learning
}

\author{
Una Cunningham, Kristy Beers Fägersten, and Elin Holmsten \\ Dalarna University, Sweden
}

Keywords: Intelligibility; online learning; e-learning; distance education; CMC; nonnative speech

\section{English for Academic Purposes (EAP) at Dalarna University, Sweden}

Ahern (2008) writes that the ability to remove the constraints of time and place is a major hallmark of computer-mediated communication (CMC) but that it also supports real-time synchronous forms of interaction. He suggests that "synchronous technologies create a strong network bond because each of the participants must be present at the same time in order to communicate” (Ahern, 2008, p. 99). Kenning (2010, p. 6), expanding on the work of Ciekanski and Chanier (2008, p. 173) would have us view the synchrony and asynchrony as a matter of degree where "face-to-face offers greater simultaneity than audio networks, audio than textchat and text chat than a shared word processor.” At Dalarna University, Sweden, we offer modes of communication at many points of Kenning's continuum with a web-based learning platform, including asynchronous document exchange and collaborative writing tools, e-mail, recorded lectures in various formats, live streamed lectures with the possibility of text questions to the lecturer in real time, textchat, and our audiovisual seminars in Marratech ${ }^{\mathrm{TM}}$ or Adobe Connect ${ }^{\mathrm{TM}}$. Our online students live in many countries around the world and come to our online learning spaces from profoundly different physical realities, so the synchronous seminar is a shared experience that is quite separate from the physical environment in which the students find themselves.

Many of our net-based English for Academic Purposes (EAP) students experience that their limited English language proficiency, compounded by technical difficulties and the constraints of the online spaces available, will sometimes cause problems in synchronous seminars. On the other hand, the rich environment of Marratech ${ }^{\mathrm{TM}}$, the desktop videoconferencing system used, offers multiple modes of communication (see Figure 1). The aim of this study is to examine the use of the multiple modes available in the seminar tool Marratech to support communication by students and teachers in a synchronous online learning environment. We describe the communication problems experienced in this kind of education and the compensatory strategies 
employed by students and teachers. We will consider situations where communication is disturbed because of

- technical problems, such as the system expelling a student, or the purchased Internet time in a public Internet café having expired, or poor connectivity;

- students not understanding the teacher because of poor sound conditions, poor perception skills in English, the teacher speaking an unfamiliar variety of English, or a combination of these;

- students not understanding fellow students usually because of limited proficiency on one or both parts, possibly in combination with the technical issues mentioned above;

- the teacher not understanding the student often because of the student's unintelligible pronunciation, in combination with less than optimal sound conditions.

\section{Context of Study}

This paper presents material from two online courses in English for Academic Purposes (EAP) at Dalarna University where students with different linguistic backgrounds meet in our seminars. At Dalarna University, we do not require online language students to attend campus at any stage. However, we do require students to attend timetabled, synchronous seminars. Most students are nonnative speakers of English, with a wide variety of first languages. The conditions under which they study vary tremendously. Many work full-time alongside their studies. Their previous knowledge and proficiency in English are also varied.

Dalarna University uses both synchronous and asynchronous channels in most online education. As Bian (2009) points out, synchronous and asynchronous media complement each other in online education. They certainly address the needs of different learner styles. Learners who have more confidence are better served by the "on-the-fly" communication required in synchronous settings, while more cautious learners may prefer asynchronous channels, which offer time for thought and editing. A balance between synchronous and asynchronous tools is helpful here. For example, being able to listen multiple times to lectures that are constantly available online is a huge advantage for a student who may not understand what was said first time around, while the real-time contact involved in a synchronous seminar enriches the communication and experienced social presence (King \& Ellis, 2009) between students and between students and teacher.

\section{Methods}

The online seminars in which this study is carried out took place using the desktop videoconferencing system, Marratech ${ }^{1}$, which was developed in Sweden. Figure 1 shows an annotated screen dump of a Marratech session in action. For more information, see Cogbuan and Kurup (2006), who offer a review of various video conferencing environments used in tertiary education. Marratech allows users to communicate using voice, moving picture via web cams,

\footnotetext{
${ }^{1}$ This company was recently bought by Google, and Marratech has now been discontinued, which forced us to abandon Marratech in favor of Adobe Connect.
} 
text chat, and whiteboard (see Figure 1). Online seminars for two EAP courses, Basic English Pronunciation and Text Studies, were recorded for the purposes of this investigation. There were 8-10 students in the seminars in the Text Studies course, with Arabic, Turkish, Swedish, Chinese, Spanish, and Persian as their first languages, and 12-18 students in the Basic English Pronunciation course, with Portuguese, Igbo, Spanish, Macedonian, Persian, Rumanian, Swedish, English, Vietnamese, and Urdu as their first languages. These courses were chosen because one dealt mostly with written material and the other mostly with the sound channel and because the students on the EAP courses typically do not have high levels of proficiency.

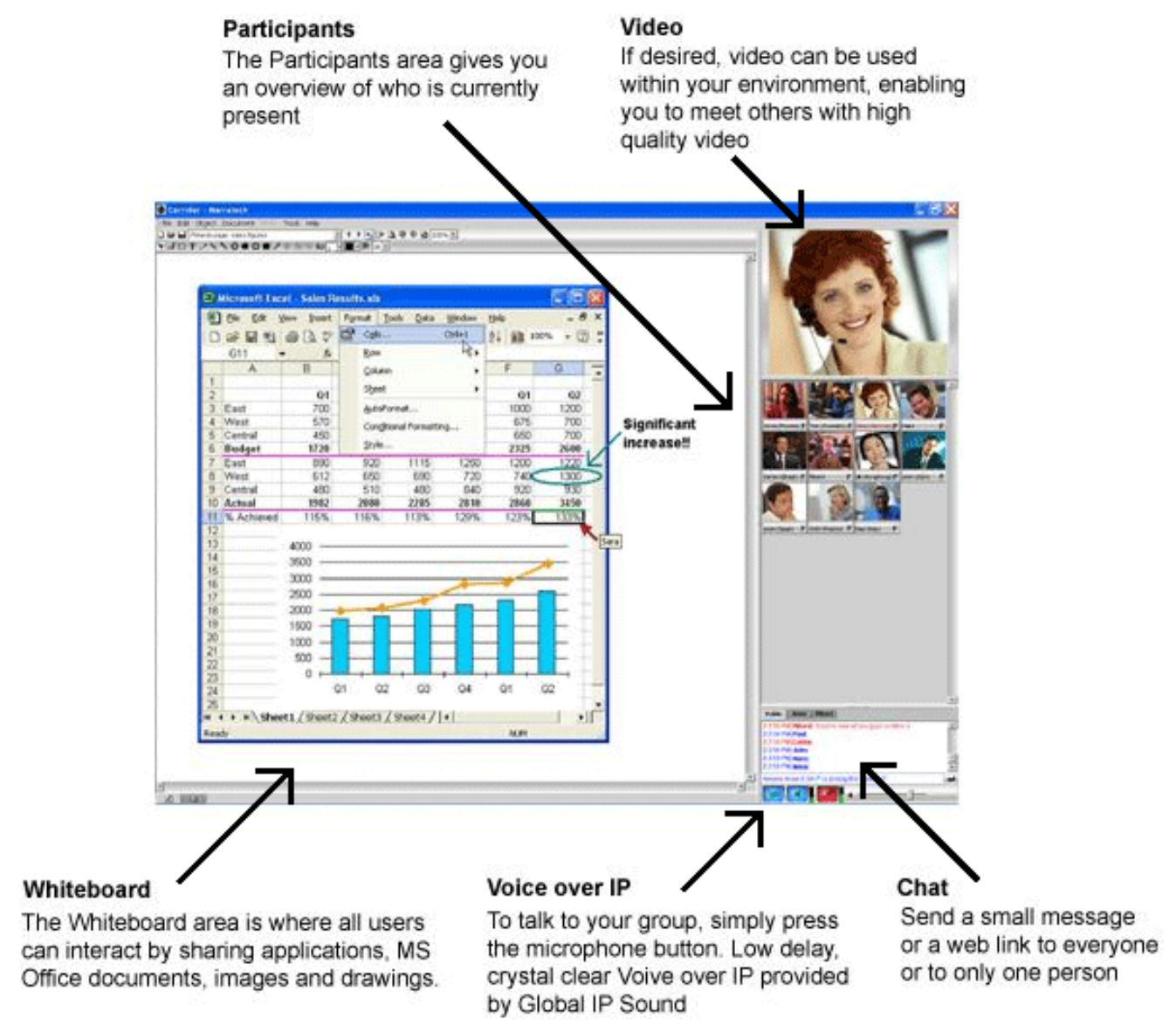

Figure 1. The Marratech seminar environment: http://www.marratech.com/

\section{Findings}

\section{Multimodality and Metacommunication}

Students may need instruction in the use of some of the functions of the seminar software, such as how to activate the pointer function, the text box, etc. This means that some time is spent every seminar on meta-modal discourse (see Beers Fägersten et al., in press), with the teacher or sometimes other students, helping other participants with the technology, such as in the following Transcript 1, a transcription of the voice communication in Marratech during a seminar, where 
almost two minutes of the seminar are used in a fruitless attempt to help one student located in Sweden to use the text box or the pointer in order to do an exercise.

Transcript 1: Meta-modal communication

10:07 Teacher: Yeah, and Student 1, you haven’t marked your word, but ah, can you show us it?

10:17 Teacher: And pronounce it for us

10:22 Teacher: Are you with us student 1?

10:27 Student 1: Yes I am trying to ah

10:32 Teacher: OK the pencil is right up by the letter $\mathrm{T}$ to the right of it. Can you see where I'm pointing?

10:44 Teacher: Otherwise you can just use the pointer and show us.

10:53 Student 1: But I cannot write

11:00 Teacher: Have you clicked on the pencil? Up here? At the top of the screen (showing with her pointer on the whiteboard). And then you just hold the mouse button down. If you click on the pencil and then just hold the mouse button down then you can write.

11:19 Teacher: Otherwise you can just click on the left mouse button and point at the word.

11:30 Teacher: Are you not getting it? Is it not working for you?

11:35 Student 1: It's not working, no.

11:41 Teacher: Can you just point with the ordinary pointer like this (showing with her pointer on the whiteboard)

11:45 Teacher: Can you just hold down the left mouse button?

11:50 Student 1: The pencil or the button?

11:55 Teacher: Have you got the pencil marked? In that case hold down the left mouse button. Then you should be able to write.

12:00 Student 1: It's not working.

Even though the problem is not resolved in this case, the use of the whiteboard tool, combined with voice instruction, is usually enough to put students on the right track.

\section{Text Chat}

In cases where there are a large number of participants in the seminar, especially if many of them are using web cams, participants may actually lose contact with Marratech from time to time or be disconnected from the room. This seems to depend on the kind of Internet connection that the individual is using. For the teacher, who will often be sitting at the University with a very fast connection, there are seldom problems, but our students work under a wide variety of conditions, and many parts of the world are still without sufficient connectivity for applications like Marratech (see e.g., Mendler, Simon, et al., 2002; Pick \& Azari, 2008). The example shown in Figure 2 is a Swedish student having difficulty. 


$\begin{array}{|ll|}{[08: 59][R]} & : \text { introduction } \\ {[08: 59][R]} & : \text { - rising to a climax- } \\ {[08: 59][R]} & : \text { - falling to the conclusion } \\ {[08: 59]} & \quad \text { : I'm back. I was disconnected from Internett } \\ {[08: 59][R]} & : \text { Who is telling the story? } \\ {[08: 59][R]} & : \text { 1st person: the narrator "I" }\end{array}$

Figure 2. Connectivity problems. A student reports his return to the seminar, entering in the middle of a side discussion using the text chat function between some students (names removed from image).

Other students, both in Sweden and abroad, attend seminars from Internet cafes or public Internet computers in railway stations and airports. There may be a lot of background noise, poor connectivity, or limited access time, as shown in Figures 3-5 below. Such disruptions obviously make it difficult for students to give the seminar their full attention.

\begin{tabular}{|l|l|}
\hline Publikt & \\
\hline$[14: 48]$ & can you pronounce future? \\
{$[14: 48]$} & thanks m8 \\
{$[14: 48] \quad$ tune } \\
{$[14: 48] \quad$ im sorry my internetticket is going out, ill be online } \\
shortly agian & ye \\
{$[14: 48]$} & -
\end{tabular}

Figure 3. Excerpt from the text chat box in a Marratech seminar. Internet time runs out (names removed from image).

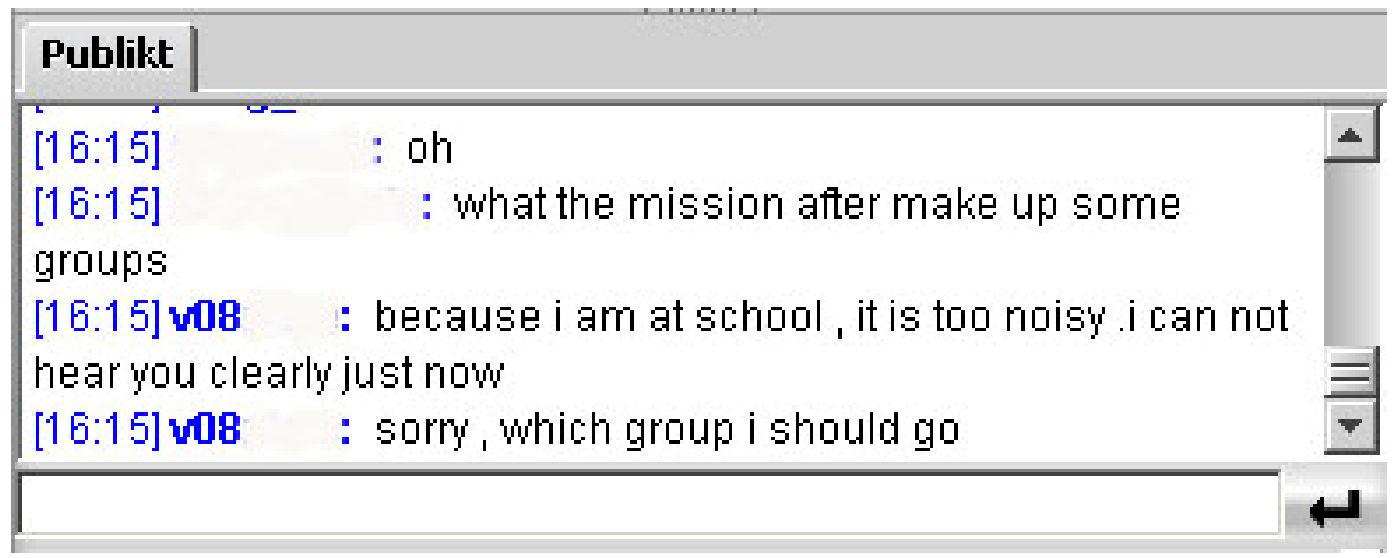

Figure 4. Noisy surroundings (names removed from image). 


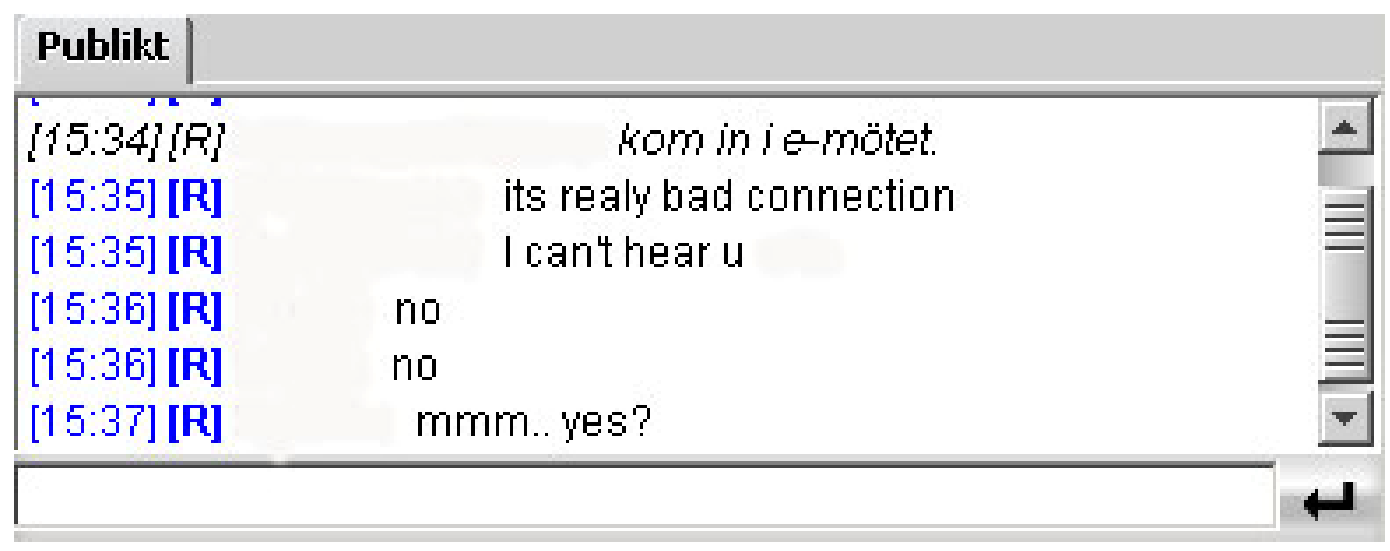

Figure 5. Connectivity problems can interfere with sound (names removed from image).

Generally, this kind of metacommunication about technical problems will be carried out in the text chat facility. In conditions with poor connectivity or inadequate equipment, the sound may break up or be inaudible, leaving the text chat as the only possible channel. It is fairly frequently the case that one or two of the students will be communicating in the chat and on the whiteboard but will not be able to use the voice channel. At the same time, the text channel is the least disruptive to the seminar itself, which may well be progressing normally for the teacher and other students.

Some students express a preference for written communication even if they have no problem using the voice channel. The written text channel gives them a little more time to respond. Yamada (2009) found that text chat in EFL teaching gave students more grammatical confidence than voice chat. This could be another aspect of the same phenomenon.

Another use of the text chat function in Marratech is that students will communicate with each other, while the teacher is talking. The chatting that goes on in the full group chat is often pertinent to what the teacher is saying. A student may ask for clarification of a term or may alert the teacher to the fact that she has not understood or heard something clearly. Sometimes another student will fill in, helping the student to understand what the teacher said. Students use the text chat for answering open questions from the teacher, particularly when they are not speaking and do not wish to ask for the floor. Figure 8 is an example of this. Notice that the last line in Figure 6 is a request from one student to another. It is directed to a native speaker of American English, who is often asked by the teacher to pronounce words as an alternative for her Northern Irish pronunciation. 


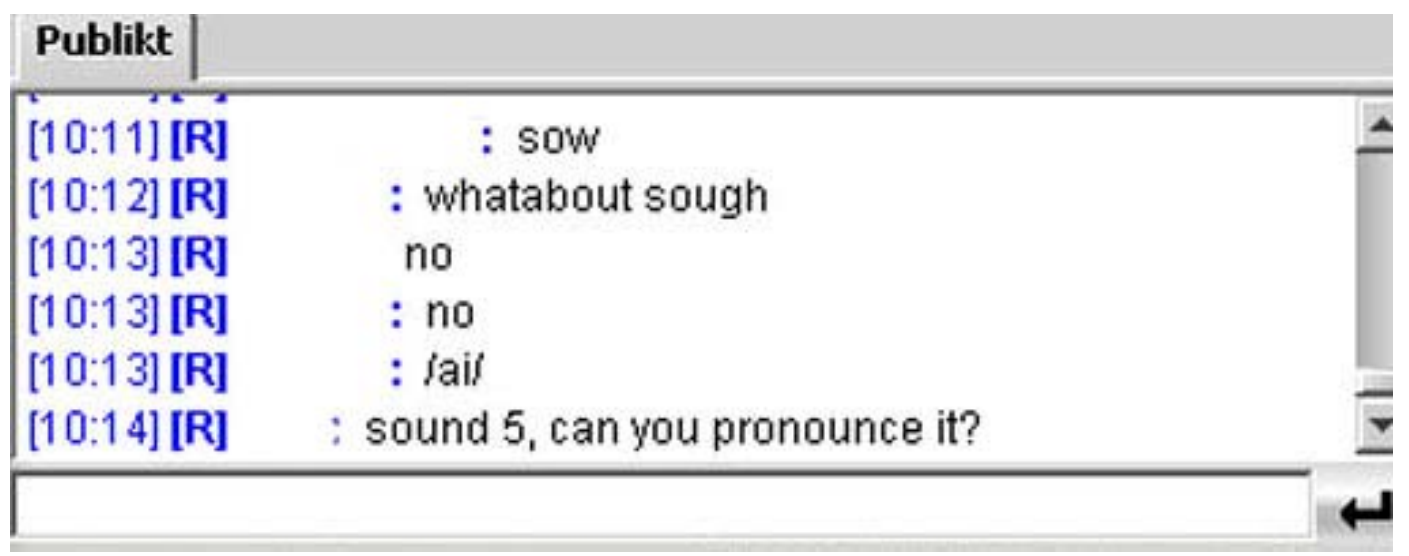

Figure 6. Answers (names removed from image).

The text chat is also used when a student or teacher adds information to what is being said on the voice channel (e.g., a relevant link). Sometimes students can be directed to sound or other material, which is available through a web page, and asked to listen to these while still in the seminar as in Figure 7.

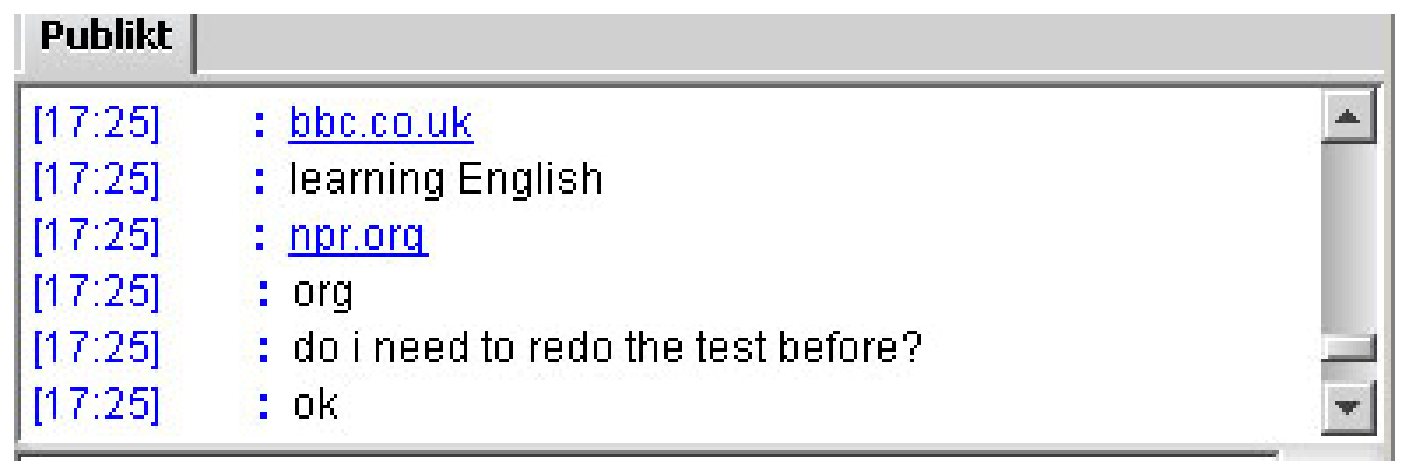

Figure 7. URLs (names removed from image).

Thus, the text chat is often used to support the oral communication in a way that is unique to this multimodal environment. There are examples of this in Figure 8, line 5 and Figure 9, lines 1 and 3. The students will also use the text chat to let other participants know when they need to step away from the computer for a while. This is of course common practice in other, nonacademic kinds of computer-mediated communication.

Text chat is also used when students are not ready to abandon a topic, even when the teacher has moved on. There is an example of this in Transcript 2. Note the use of capitals in BUT IT IS WRONG, a graphical representation of a raised voice. 


\section{Transcript 2: Heated debate}

Teacher: Yes, Student 6 wrote a nice comment there - student 6, would you like to comment on that?

Student 6: Yes, I mean, it just glorifies and celebrates war. [... unclear...] I do not know the background of this project ah. I think that people want to strike for the common good and the American dream.

Student 7: I think you talking about a nation, not a continent, because I mean, America is a continent.

Teacher: You think he is talking about a continent?

Student 7: I think he is writing about a continent, because he talks about a nation. Or he think that America is not a nation?

Student 8: Maybe he think it a nation. I dunno.

Student 7: Yes, but a nation have a name. What is the name of United States of America?

Teacher: For many Americans, maybe most Americans it is America, and they do not think about it. Maybe then they are actually talking about the whole continent? They say America when they mean their country

Student 8: Yeah I know but it is wrong.

Teacher: (changes subject)

Student 8: (in chat box) BUT IT IS WRONG. America is a continent

Student 9: (in chat box) it is both. A country that is also known as USA and the continent divided in three parts

As well as the public chat, Marratech also has a function whereby two participants can have private chats with each other. Students use this as a way of "whispering in class." Sometimes this private communication will be purely social, but very often students discuss what is being said in class. We know this because a student may refer to a discussion in a private chat when asking the teacher a question. One student might be asking for clarification, or perhaps the students are discussing a case exemplifying what the teacher is talking about.

\section{The Video Channel}

The video image in Marratech is not refreshed frequently enough to be perceived as synchronized with the speech. This means that listeners cannot support their listening with lip reading, as would be the case in face-to-face communication. By the same token, gesture and body language cannot easily be used to support communication in Marratech seminars, although facial expression may be useful. Yamada (2009) comments on the role of video feedback, such as nodding or shaking the head, to let speakers know whether or not they are making themselves understood.

To minimize background noise, students are requested to keep their microphones off when they are not speaking. This has the unfortunate side-effect of casting the teachers in an atmosphere of total silence. If, in addition, many participants have no webcam on, the teacher may feel that she is on her own entirely and she may need to elicit an explicit confirmation from students, as in the 
plaintive "Can you hear me, Hanoi" of the title, or as in Transcript 3. From the teachers' perspective, webcams give feedback, letting them know if they have the attention of the students and if they are making themselves clear (Slovak 2007). If the students are using webcams, it is easy for the teachers to see that they are still paying attention and are active in the class. Without webcams, many teachers frequently address students by name, asking for responses. In situations where seminar attendance is compulsory and seminar participation contributes to the student's grade, it is important that student activity can be monitored.

Transcript 3: Teachers need feedback too.

Teacher: Student 2 can you hear me? Student 2?

Student 2: Yes, I can hear you

Teacher: Oh, great!

Student 2: You sound surprised

Teacher: Well, for a while there I could not hear you

Student 2: Yeah, right

Teacher: Yeah, so uh, what can you say about the difference between fiction and nonfiction?

Many students are strangely reluctant to use webcams. This might be attributed to the perceived anonymity of computer-mediated communication, with its associated disinhibition effects (Suler 2004). Thurlow, Lengel, et al. (2004) point out that being or feeling relatively anonymous in CMC entails both a perception of freedom from constraints and of freedom from responsibility, such that people can feel less self-conscious about their appearance and more inclined to disclose things about themselves. The opportunities made available by CMC for misrepresentation or obfuscation of the self (see Joinson, 2003, pp. 78-79) may be more relevant to social networking than to educational applications of CMC, but this distinction may not always be apparent for students or indeed those educators who embrace the use of avatars and pseudonyms in environments such as Second Life, as described, for example, in recent work by Cliburn and Gross (2009) and Foster (2008). It has been found that students who experience social anxiety see the Internet as a useful channel for social engagement (Shepherd \& Edelmann 2005). Rice and Markey (2009) and High and Caplan (2008) found that anonymous text chat conversations with strangers were perceived as less stressful than similar face-to-face conversations. Senem (2009) found that students found it difficult to see their classmates as real at the beginning of the course and that they actively looked for pictures of their classmates to have an idea what they looked like, suggesting that visual information about fellow students and teachers may be important for constructing a perception of social presence.

The video channel can also be used for clarification purposes. In Figure 8, the teacher wants to indicate that the first sounds of the words the and three are different. Since it is not possible to write International Phonetic Alphabet (IPA) symbols in the Marratech whiteboard or text chat box, holding up this sheet to the camera is a useful alternative and yet another example of how the multimodal Marratech environment can achieve efficient communication in the face of technological challenges. 


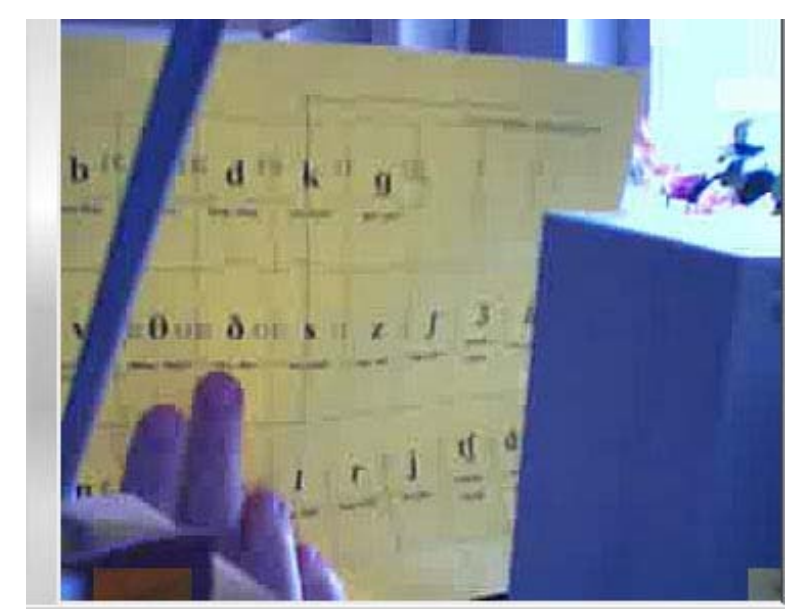

Figure 8. This is the symbol I mean.

As long as the teacher keeps the limited refresh rate in mind, it is in fact possible to use the camera to demonstrate aspects of pronunciation in Marratech. Particular sounds of English, such as the interdental fricatives, can be usefully shown using the camera as long as the teacher is prepared to pronounce the sound in slow motion.

\section{Voice Channel}

In synchronous seminars in Marratech, the voice channel is primary and is used extensively by both teachers and students. If the students cannot make themselves understood on the voice channel, this can be compensated for by using text chat, but a student who cannot hear the voice channel will not be able to take part in the seminar. In a study of asynchronous communication in online education, King and Ellis (2009) found that the addition of a voice channel does not add to the social presence perceived by students. This is not in line with the findings of Rothwell (2008) and Salmon and Nie (2008), who looked at various kinds of podcasts used for asynchronous voice communication in blended learning contexts where the podcasts were very positively received. In synchronous communication, of course, the position is another. The interlocutor is there, in real time, and voice does add a dimension of closeness and contact between participants, given the paralinguistic information it contains in terms of emotion, pace, sociogeographic background, personality, etc. Yamada (2009) found that voice communication had a strong effect on learners' output, making learners aware that they are, in fact, taking part in natural communication with real interlocuters. Lamy and Hampel (2007), however, found that synchronous environments seem to stress learners, making them speak more quickly and in short sentences, which may not be conducive to language learning. It seems likely that this will depend on the student group. If many students are keen to speak in the seminar, there will be pressure to hold the floor.

Nonnative listeners are, as has been documented by previous work (Mayo, Florentine, et al. 1997; van Wijngaarden, Bronkhorst, et al. 2004; van Wijngaarden, Steeneken, et al. 2002, Hazan \& Simpson 2000; Takata \& Nabelek, 1990), particularly susceptible to the effects of noise. Transcript 5 shows one such case where a Chinese student in China has (possibly unwittingly) pressed the microphone button, which then turns red, an often used signal from students that they 
want to say something. She has poor sound quality compounded by a heavy accent and finds it difficult to make herself understood. The teacher is faced with either asking the student to repeat what she said again or to write her question in the chat box, or he can just let it go, which is what happens in Transcript 4.

Transcript 4: I didn't quite get that.

(The teacher has asked the students to find synonyms for silent. The last word mentioned was dumb. Student 8 presses the mike button briefly. Background noises heard)

Teacher: Ah student 8?

Student 8: Yes?

Teacher: Did you want to say something?

Student 8: (heavy Chinese accent) Yes, I said, what is [unclear] wordlist? What about the wordlist?

Teacher: mm, I didn't quite get that

Student 8: I am not sure that right.

Teacher: Ah, um, yeah, dumb can be a touchy word to use. It can also mean stupid, especially in American English

Transcript 5 is an example where one of the students was speaking fairly quietly and another student asked for clarification. Although the students were apparently able to resolve the difficulty themselves, the teacher stepped in and expanded what had been said in an attempt to lead students to a different interpretation.

Transcript 5: What did Student 1 say?

Teacher: What did he mean by a yellow wood? "Two roads diverged in a yellow wood."

Student 2: So that you mean is a meaning with the color yellow or?

Teacher: Yes

Student 1: (low volume) It could mean the sun?

Teacher :Ah! Other suggestions?

Student 2: I sorry I didn’t hear. What did she say? What did Student 1 say?

Student 1: (louder) The sun.

Student 2: Ah, the sun.

Teacher: Yeah, the sun shining through the trees and the leaves down. Oh it can be so beautiful. And um could also be a certain time of the year?

Student 1: The fall?

Teacher: Yes

The voice channel is quite sensitive to connectivity problems as well as other technical problems, with occasional poor sound quality, including hum, buzzing, screeching, and low-volume as well as distorted or intermittent sound. In such conditions, the compensatory visual mechanisms available in Marratech are necessary. 


\section{The Whiteboard}

In pronunciation teaching, one of the exercises used to practice clear speech in the face of a relatively unintelligible pronunciation requires students to read one of a number of potentially easily confused utterances, while their fellow students attempt to identify which of the alternatives has been read. An example of this, part of a screen dump showing the whiteboard, can be seen in Figure 9 below.

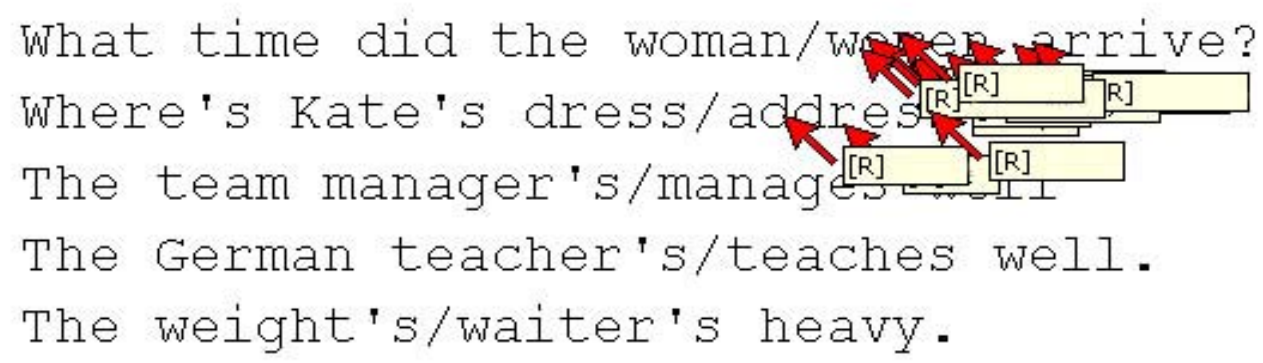

Figure 9. What did I say? Woman or women? (names removed from image).

Using the individual pointers, which ordinarily have the student's name on the pointer label, it is possible for students to indicate which of the written words they heard. Students who are unsure can wait until other students have made their choice. Marratech's whiteboard facility can be used in this way to support and supplement oral communication during a seminar (see Xinyou, Yanru, et al., 2006).

In Figure 10, students are responding to an exercise in sound identification. The teacher points at a word in the list on the left; in this case, the word the has just been dealt with, and a named student pronounces the word. The other students then indicate on the whiteboard, which, if any, of the five possible IPA symbols correspond to the sounds they heard. In the example shown, the students were not agreed on which of the sounds they heard. (In fact none of the sounds were in the word the in this context.) 
Ididn't see the third match

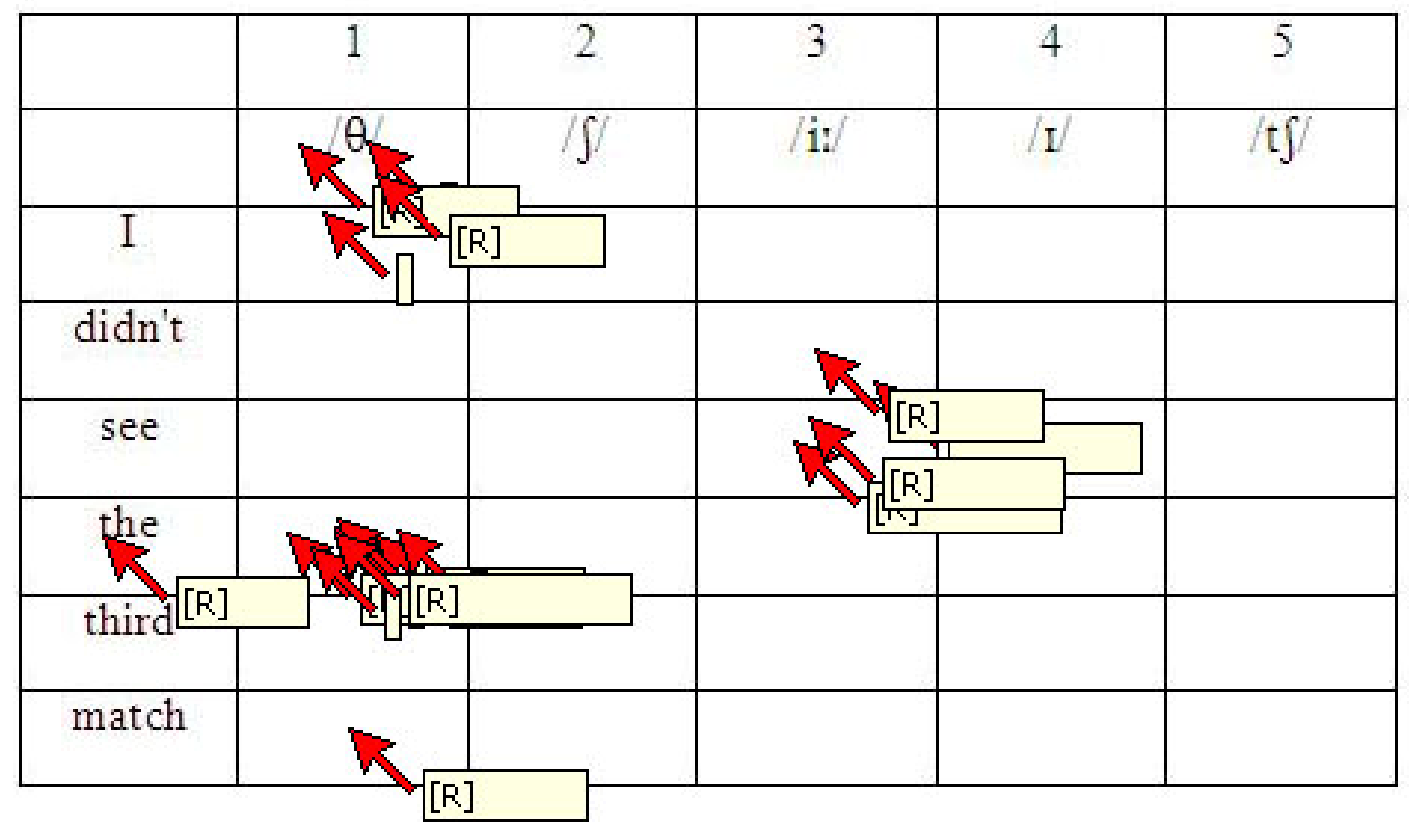

Figure 10. Using IPA symbols on the whiteboard (names removed from image).

The use of the visual element of the students' individual pointers on the whiteboard allows a collaborative way of working that is not possible in face-to-face teaching. Everyone is involved, working simultaneously on the task at hand.

\section{Discussion}

It is apparent that there are many ways in which students and teachers can fail to understand each other in Marratech seminars. As described by Jenkins (2002), more is required of the learner who needs to make him or herself understood to a group with mixed language backgrounds than in cases where a class has a common first language. It is not possible for the learners to rely on their common language background to facilitate communication. Features of pronunciation that are associated with a particular first language background will not often be helpful in communication with those who do not share this language background. Nonetheless, most of the time communication does actually work in the seminar. The participants are very creative in finding ways to compensate for their communicative failing, using the modes in the Marratech environment. Net-based teaching carries with it a set of constraints and a set of possibilities. Depending on which of the available tools we use at any given time, the constraints and possibilities will be different. Synchronous online seminars are an essential part of net-based language learning and teaching at Dalarna University. They provide an aural component to learning, which is obviously essential in modern, communicative language learning and teaching. They also provide real-time contact between teachers and students, and, in fact, our net-based courses are very similar to campus courses. Our campus students use the learning platform in the same way as the online students and will often interact with the online students in forum 
discussions. The only difference is that the campus students come to campus for the seminars, while the net-based students go to the virtual seminar rooms of Marratech.

Many universities have moved into the field of net-based teaching. But not all universities are willing to undertake language teaching online. One reason for this may be that they view netbased teaching as a primarily text-based activity. In such cases, net-based teaching is simply a 21st-century version of correspondence classes. This is clearly not suitable for modern language learning and teaching, nor indeed, arguably, for any modern learning activities. A modern communicative approach to language learning requires both synchronous channels and voice, although text-based and asynchronous communication channels are also necessary to develop written proficiency and to enable students to develop proficiency in less spontaneous forms of communication. As new generations of software are developed, new pedagogical activities will follow.

The problems experienced by learners of English in the kinds of EAP settings we have described here are both exacerbated and ameliorated by the computer-mediated channels open to learners and teachers. Patchy connectivity, poor quality equipment inexpertly used, the lack of a synchronized video channel, and less-than-perfect software compound the fundamental proficiency deficits which limit the perception and production of our students. However, the multimodality offered by the software enables students and teachers to compensate for these problems in a way that more than makes up for the disadvantages.

Net-based language learning and teaching is a demanding application for new technology, but pedagogical considerations must be at the center, not the technology. Nevertheless, new technologies will inspire new pedagogical approaches. This study concerns a particular synchronous environment for online seminars. Other software will offer other possibilities and other challenges for students and teachers. Technological advances will quickly enable these environments to be refined, making their limitations less problematic as well as adding new functions, which can be filled with pedagogical content for the benefit of students.

\section{Acknowledgements}

This work was supported by grant 2007/0255 from the Swedish Knowledge Foundation. We are grateful to the students and teachers who allowed us to use material from their seminars. 


\section{References}

Ahern, T.C. (2008). CMC for language acquisition. In F. Zhang \& B. Barber (Eds.), Handbook of research on computer-enhanced language acquisition and learning (295-306). Hershey: Information Science Reference.

Beers Fägersten, K., Holmsten, E., \& Cunningham, U. (in press). Multimodal communication and meta-modal discourse in the video-conference environment. In R. Taiwo (Ed.), Handbook of research in discourse behavior and digital communication: Language structures and social interaction. Hershey: IGI Global.

Bian, L. (2009). Application of digital technology in open and distance education. 2009 International Conference on Networking and Digital Society 1 (pp. 273-276).

Ciekanski, M., \& Chanier, T. (2008). Developing online multimodal verbal communication to enhance the writing process in an audio-graphic conferencing environment. ReCALL 20(2), 1-8.

Cogbuan, D.L., \& Kurup, D. (2006). The world is our campus. Network Computing, 17(7), 57-64.

Foster, A.L. (2008). Professor Avatar. Education Digest, 73(5), 12-18.

Hazan, V., \& Simpson, A. (2000). The effect of cue-enhancement on consonant intelligibility in noise: Speaker and listener effects. Language and Speech, 43, 273-294.

High, A.C., \& Caplan, S.E. (2009). Social anxiety and computer-mediated communication during initial interactions: Implications for the hyperpersonal perspective. Computers in Human Behavior, 25(2), 475-482.

Jenkins, J. (2002). A sociolinguistically based, empirically researched pronunciation syllabus for English as an international language. Applied Linguistics, 23(1), 83-103.

Joinson, A.N. (2003). Understanding the psychology of internet behaviour. Basingstoke: Palgrave Macmillan.

Kenning, M.-M. (2010). Differences that make the difference: A study of functionalities in synchronous CMC. ReCALL, 22(1), 3-19.

King, K., \& Ellis, T.J. (2009). Comparison of social presence in voice-based and text-based asynchronous computer conferences. 42nd Hawaii International Conference on System Sciences, 1-10.

Lamy, M.-N., \& Hampel, R. (2007). Online communication in language learning and teaching. Basingstoke: Palgrave Macmillan. 
Mayo, L.H., Florentine, M., \& Buus, S. (1997). Age of second-language acquisition and perception of speech in noise. Journal of Speech, Language and Hearing Research, 40, 686-693.

Mendler, J., Simon, D., \& Broome, P. (2002). Virtual development and virtual geographies: using the Internet to teach interactive distance courses in the global South. Journal of Geography in Higher Education, 26(3), 313-325.

Pick, J.B., \& Azari, R. (2008). Global digital divide, Influence of socioeconomic, governmental, and accessibility factors on information technology. Information Technology for Development, 14(2), 91-115.

Rice, L., \& Markey, P.M. (2009). The role of extraversion and neuroticism in influencing anxiety following computer-mediated interactions. Personality and Individual Differences, 46(1), 35-39.

Rothwell, L. (2008). Podcasts and collaborative learning. In G. Salmon \& P. Edirisingha (Eds.), Podcasting for learning in universities (pp. 121-131). Maidenhead: Open University Press.

Salmon, G., \& Nie, M. (2008). Doubling the life of iPods. In G. Salmon \& P. Edirisingha (Eds.), Podcasting for learning in universities (pp. 1-11). Maidenhead: Open University Press.

Senem, Y. (2009). Social presence in the web-based classroom, implications for intercultural communication. Journal of Studies in International Education, 13(1), 46-66.

Shepherd, R.-M., \& Edelmann, R.J. (2005). Reasons for internet use and social anxiety. Personality and Individual Differences, 39(5), 949-958.

Slovak, P. (2007). Effect of videoconferencing environments on perception of communication. Cyberpsychology, 1(1).

Suler, J. (2004). The online disinhibition effect. Cyberpsychology and Behavior, 7(3), 321-326.

Takata, Y., \& Nabelek, A.K. (1990). English consonant recognition in noise and in reverberation by Japanese and American listeners. Journal of the Acoustical Society of America, 88, 663-666.

Thurlow, C., Lengel, L., \& Tomic, A. (2004). Computer mediated communication. London: Sage Publications.

van Wijngaarden, S.J., Bronkhorst, A.W., Houtgast, T., \& Steeneken, H.J.M. (2004). Using the Speech Transmission Index for predicting non-native speech intelligibility. Journal of the Acoustical Society of America, 115(3), 1281-1291. 
van Wijngaarden, S.J., Steeneken, H.J.M., \& Houtgast, T. (2002). Quantifying the intelligibility of speech in noise for non-native listeners. Journal of the Acoustical Society of America, 111(4), 1906-1916.

Xinyou, Z., Yanru, Z., \& Matsumoto, M. (2006). A real-time interactive shared system for distance learning. Multi-Media Modelling Conference Proceedings, 12th International, 102-107.

Yamada, M. (2009). The role of social presence in learner-centered communicative language learning using synchronous computer-mediated communication, Experimental study. Computers and Education, 52(4), 820-833.

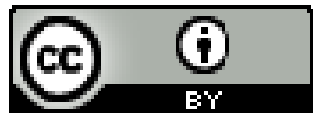

